\title{
Confrontational Behavior and Escalation to War 1816-1980: A Research Plan
}

\author{
J. DAVID SINGER \\ University of Michigan
}

\begin{abstract}
The understanding of international war, like many complex social events, may be - and has been - approached from a range of theoretical perspectives and via a variety of research strategies. Outside of the work of Bloch (1898), Sorokin (1936), Richardson (1941), and Wright (1942), however, there was little research of a scientific nature until the mid-1960s. And while these past fifteen years have certainly not given us a compelling theory of international war, they have seen a steady growth in cumulative knowledge regarding the correlates of war. These results, despite the expected mix of inconsistencies and anomalies, provide us with some sense of the factors that are most consistently associated with war over the last century and a half, along with some tentative insights into the rising and declining potency of these factors.
\end{abstract}

\section{Introduction: the problem and prior research}

In an earlier paper on the state of the discipline (Singer 1981), we have summarized and interpreted virtually all of the data-based work on the causes, correlates, and conditions of modern international war, and certain theoretical implications seem to emerge from that largely North American enterprise. Two of these are of particular interest here as we propose some next steps in the search for explanation of this relatively rare, but increasingly destructive form of global conflict. One is that models built around $x$ ational attributes do little in accounting for the distribution of war across cases, regions, and time. If researchers have been looking at the appropriate dimensions, there does not seem to be a distinctive war-proneness profile (Richardson 1960; Rummel 1972). Nations with a dazzling variety of political, economic, and social institutions and practices are found in fairly equal numbers in the high and the low war frequency categories; nor does there seem to be a discernible trend over time. The only consistent finding is the obvious one that the more powerful are the more war-prone (Bremer 1980), and that the major powers clearly dominate in this area of activity. Beyond industrial and military capabilities, however, it seems to matter not whether the economy is state controlled or market oriented, or the wealth is equally distributed or highly concentrated, whether the people are culturally homogenous, quite diffused, or isolable into two or three clear groupings, and so on.

This is not to suggest that national security policies are fully determined by external stimuli or that domestic politics are of no consequence. Rather, it would seem, we have been too busy looking at the sorts of variables that the comparative politics texts use to distinguish between nations. Our objective, however, is not to describe national societies but to account for their foreign and security policies. If we think of these policy elites as operating at the interface between the domestic and the external settings and trying to cope with the demands and constraints generated by each, the idea of interest articulation and aggregation comes readily to mind. Decision makers move in and out of foreign conflict and toward or away from the brink of war in response to well-articulated orientations (Holsti 1979), interests, and needs (Choucri and North 1975), including, of course, their own. As our research moves away from goodness of fit criteria to the confirmation of increasingly explanatory models, we will want to return to other domestic variables (as in $\mathbf{M}$. Haas 1965), but in the work proposed here we will restrict ourselves to that of military and industrial capabilities.

Shifting to the dyadic level of aggregation, 
the evidence is quite to the contrary, and many of these variables seem quite potent in accounting for the incidence of war. Defining this dimension in the sense of both similarities and interdependencies, the dyadic variables seem to discriminate rather powerfully between war and no war outcomes when states are in conflict or confrontation.

Similarly, we and others have found that the properties of the international system help to account for the incidence of war (Garnham 1979; Sullivan 1978). To take one of the more persuasive findings, Singer and his colleagues (1972) have accounted for nearly $80 \%$ of the variance in international war from 1816 through 1965 by looking only at the degree to which military and industrial capabilities among the major powers are concentrated in the hands of one or two such powers, along with the direction and rate of change therein.

In any event, there no longer seems to be much doubt that the incidence of war can indeed be explained, and the question now is not so much whether we can, but how to best go about it. As suggested in the above summary, one of the choices we face is that of the level of aggregation: the national, the dyadic, and the systemic, and in the design that follows, we clearly opt - on the basis of previous findings - for the latter two. A closely related choice is that of proximity to the events that we seek to explain. Whereas some would contend that we will do better by focussing on the conditions and events that occur just prior to the denouement of war or no war in an international confrontation, others might suggest that we ought to attend to those conditions and events that are further away, in space as well as in time, from the outcome phenomenon. Often this perspective rests on the premise that the 'die is cast' well before the decision, and that the actors are well on the road to one or another outcome in the months that precede it and by dint of the factors that obtain in the larger environment.

Up to now, we have generally accepted this line of reasoning, and as already indicated, not without success. But it is one thing to achieve a good fit between one's predictive model and the observed historical patterns, and quite another to achieve an explanation of that fit. Thus, we are now moving into a research phase that should further close the gap between observed correlations and compelling explanations. To do that, of course, one must introduce behavioral variables into what has been an essentially ecological type of model.

\section{The general plan and rationale}

Thus, the next two years of work in the Correlates of War project will be addressed to four sets of research activities. First, given the above considerations, and in light of what has been disovered regarding those national, dyadic, and systemic conditions that are associated with war (Zinnes 1980), we will integrate these results into a more general statistical model in order to account for the war and no war outcomes in our population of military confrontations.

Up to now we have relied primarily on contingency table analyses and a partitioning strategy such that we can best discriminate between the war and no war outcome cases. The strategy and findings were delivered at the recent IPSA Congress in Moscow (Singer 1979). Second, we will try to account for the behavior patterns that ultimately link those ecological and contextual factors to the war and no-war outcomes. To do this, we have to identify the universe of military confrontations that have occurred between and among all members of the international system since the Congress of Vienna; those involving one or more of the system's major powers $(\mathrm{N}=299)$ have already been identified, and the balance (about 600 more) have been identified by systematically coding the diplomatic histories of each sovereign nation during its tenure in the system. A military confrontation, in turn, is defined as a conflict in which each protagonist has done at least one of the following: a) made an explicit threat to resort to military force, b) mobilized or re-deployed its military forces, or c) actually resorted to force short of war.

For the confrontations to be classified as 
having escalated to war, there must have been sustained military hostilities involving the regular armed forces of both sets of protagonists leading to at least 1000 battle-connected fatalities. The wars $(\mathrm{N}=115)$, the coding criteria, and the data sources are reported in The Wages of War (Singer \& Small 1972, and the revised edition, forthcoming).

Once the confrontations and their outcomes are fully identified, we code all the confrontational acts taken by all the protagonists, specifying which type of act was taken when, by which party, and toward whom. The coding criteria and rationale are reported in Leng and Singer (1977), and inasmuch as the onset of a confrontation as well as its ensuing acts are all coded at the same time, that data base has also been completed for the major powers and will soon have been completed for the balance of the system's members.

Once these behavioral data have been generated, and we have ascertained the extent to which they can be explained by the ecological model, we will integrate them into the original ecological/contextual model. That is, once we better understand which behaviors occur under which systemic, dyadic, and national conditions, we will shift to our third phase, developing a computer simulation model that can reveal which combinations of behavioral and ecological variables best discriminate between the war and no-war outcome during the several historical periods. With those data sets generated, the statistical analyses completed and the simulation model running, we will turn to the fourth set of activities: integrating the ecological and behavioral sub-models into an overall model with simulated decision rules that should carry us another step closer to an explanation of why certain military confrontations end in war (about 13\%) and why the balance do not.

Rather than summarize the theoretical model earlier, or even at this juncture, we postpone that until the final sub-model is discussed. This sub-model is, of course, the decisional one; representing an effort to bring together the background ecological factors and the behavorial patterns on the one hand and the outcome of war or no-war on the other. As we see it, this task of closing the explanatory sequence may be approached from three methodological perspectives. The most ambitious is to try to get at the entire decision process, using such traces as detailed minutes, the memoirs of all the participants, or more recently, films or tapes of all the proceedings. Needless to say, this is virtually impossible either for the early 19 th or the late 20 th centuries; any traces of the interactions of the participants would invariably be incomplete and potentially very misleading. A second strategy is to get at the perceptions, preferences, and predictions of the individual participants (Axelrod 1976; Singer 1968; Stewart 1976), but even if the researcher could obtain that sort of information, coding and analyzing it would not be very helpful, inasmuch as it would reveal little about the interactions among the individuals. Yet a third mode and the one utilized here - would be to simulate the decision process, and we use the word simulation rather than representation quite consciously (Alker and Brunner 1969; Barton 1970). That is, the purpose is not to recreate and represent the decision makers' interactions, but to generate and test a variety of hypothetical decision rules that turn out to be consonant with those that could be in operation, given the observed ecological and behavioral inputs and the observed war/no-war output. To put it differently, the objective is not to specify, but to abstract from, the decision process such that the inputs and outcomes can be linked via an 'as if' process. If a given set of decision makers respond in a given way to a given set of stimuli, we can say that, while we could not observe their decision process and thus identify their decision rules directly, they behaved as if they were following a particular strategy and the decision rules implied by that strategy (Simon 1969). We emphasize that, for general predictive purposes, one can be fairly successful with a model that 'merely' specifies which behaviors arise out of a given confrontational context, and which combinations of context and behavior typically eventuate in war. But if we hope to 
go beyond mere prediction and achieve a degree of explanation, it is essential to probe the black box and try to identify the decision rules and algorithms that best account for the context-behavior-outcome sequences (Whiting 1975). Further, the accuracy of predictions resting upon an explanatory model, reflecting as they do the changing relations among the variables, will usually be greater than those that rest on simple post-dictions and unexplained deviations therefrom.

\section{The model and its variables}

Having summarized the general research plan, let us turn next to the overall model and its basic variables; following that we will address the decisional sub-model in greater detail.

As already indicated, our central objective in the next two years is to differentiate as precisely as we can between two types of interstate military confrontation: those that ended in the sustained combat of war and those that found (however temporarily) a less violent outcome. To achieve that differentiation, we will focus on three sets of variables: a) the properties of ten global and regional system within which the confrontation erupts and unfolds; b) the dyadic relationship that binds the protagonists, contrasts their capabilities, and constitutes their prior involvements with one another; and c) the escalatory and de-escalatory moves that the protagonists take from the beginning of the confrontation to its denouement.

We proceed from three critical assumptions:

a) the international system is, by the nature of its structure and culture, a moderately conflictful one in which scarcities of a material and symbolic sort abound, and in which neither the institutions nor the norms that might encourage coordination of national interests across rival states and blocs exist in sufficient strength;

b) the range of issues over which national governments can get into serious disputes is exceedingly wide, but once the dispute becomes militarized, those issues diminish in importance and are overshadowed by the fundamental preoccupation with material and symbolic security;

c) given the onset of a military confrontation, domestic and bureaucratic considerations limit the repertoire of possible moves and counter-moves, thus diminishing the autonomy of the protagonists and increasing the potency of the contextual factors.

Given these assumptions regarding the onset of a military confrontation, we turn next to the three sets of critical variables that are expected to affect its outcome, indicating their expected separate effects, ceteris paribus. Perhaps most potent are those at the dyadic level, with the following five seen as playing the dominant role in determining the outcome of the confrontation.

First in potency is that of the relative capabilities of the protagonists, measured primarily in terms of military expenditure, personnel, and a weapons lethality-survivability index (Dupuy 1979); all else being equal, the model says that the nearer the protagonists are to equality, the greater the likelihood of escalation to war. Next is the geographical contiguity of the actors to one another and to the site of the confrontation; proximity is seen not only as enhancing the capabilities of one or both sides, but also as raising the incentive to escalate. Third are the military alliances, reflecting the likelihood of $\mathbf{n}^{\text {th }}$ parties intervening on one or both sides and thus changing the relative capabilities as well as the incentives and constraints toward escalation. We assume, and the evidence partially confirms, that formal alliances with $\mathbf{n}^{\text {th }}$ parties serve as a constraining force in confrontations. Fourth, and closely related, are the bonds and links between the protagonists themselves; the links of trade and alliance are seen, again with some modest empirical support, as conducive to escalatory behavior, however inhibiting they may be in reducing the frequency of military confrontation (Gochman 1980; Singer 1979). As to past interactions, fifth, the effects are seen to be mixed, reflected in 'learned' responses to successes and failures in previous confrontations and wars; the limited evidence 
suggests that prior failures are more likely to inhibit bellicosity than exacerbate it, despite the plausibility of either assumption.

Turning to systemic factors, at the regional as well as the global levels, three basic ones concern us here. The first is structural clarity, by which we mean the extent to which the coalition configurations and the capability rankings in the system are sufficiently clear to permit confident predictions by decision makers as to which states will line up with whom if the confrontation goes to war, and the combined capabilities that would be arrayed (Singer and Bouxsein 1975). While the evidence is mixed, we see clarity here as exercising a benign effect, and ambiguities as conducive to escalation. A closely related systemic factor is concentration: the extent to which the region's (or globe's) resources (ranging from industrial and military to diplomatic and cul. tural) are equally distributed or concentrated in the hands of a few dominant states. While high concentration may bode ill for social justice, it seems to exercise a restraining effect upon confrontations that occur in its presence. Next is systemic interdependence, reflecting the extent to which the regional or global system's members are linked together via trade, diplomatic, alliance, or international organization bonds, and here there is little empirical evidence and most of that is weak. However, with some of the neo-functionalists (Keohane \& Nye 1977), we postulate interdependence (and its more developed version, integration) as exercising an essentially benign and restraining effect on escalatory behavior.

Whereas these three sets of variables are structural in character and show fluctuations over time, the other two are material and cultural respectively, and they show rather steady secular trends rather than fluctuations across time. Thus the fourth is that of material resource availability in the system and is measured in terms of the amount of land, resources, and markets that are not yet (at the time of the confrontation) fully controlled by sovereign states. The smaller the remaining amounts, the more the 'frontier has been closed,' and the greater will be the propensity to escalate. Similarly, the fifth factor, while cultural in nature, also shows a secular trend, but in the opposite direction (Kegley 1979). We refer to the disapproval of military force as an instrument of state policy, and measure it in terms of the fraction of states in the regional or global system that score at certain levels on an illegitimacy of war scale. As implied earlier, we do not expect, and have not found, all of our relationships to be constant across time, and some preliminary examinations suggest that factors such as these latter two may be accounting for certain of our parameter shifts, especially those that occur around the turn of the century.

Turning finally to national level attributes (as distinct from behavior), we have already indicated that material capabilities seem to be the only one that systematically discriminates between low and high war-proneness. In the model at hand, national capabilities are translated into dyadic comparisons, and the working assumption is that the nearer the protagonists are to parity, the greater the probability of escalatory behavior. And in the Methods and Procedures section we discuss the indicators that are being developed and tested.

Having summarized the key variables in the ecological model and indicated the individual role that each is expected to play in the unfolding of military confrontations, we now suggest in broad terms how these factors flow into and impinge upon one another in these brink-of-war episodes. Very simply, our variables fall into one of two theoretical categories and their role in the model is a function of those categories.

On the one hand are the variables that represent the stakes in the confrontation and the dispute that preceded it. The stakes can be of two sorts: hopes and fears. By hopes, we mean those outcomes that the protagonist's decision makers would like to achieve and acquire, and by fears we mean those outcomes they would like to avoid. Hopes are the gains that the decision makers seek, and fears are the losses that they strive to prevent. Thus, we postulate that our simulated decision makers will be motivated by the prospects and proba- 
bilities of gaining or losing territory, resources, markets, allies, prestige, credibility, and the like (Wright 1965).

The crucial element is not only one of how salient and valued the stakes are and what utility and disutility scores will be assigned to each projected (hoped or feared) outcome of the confrontation; it is equally a matter of probabilities. The subjective likelihood of success and of failure is seen as interacting with the value (positive or negative) they assign to the possible outcomes, thus generating the familiar 'expected utilities.' The above, then, outlines the general model, its key variables, and the postulated interactions among them. To this juncture, we will rely heavily on a range of statistical methods for best identifying the separate and combined effects of these ecological variables on the behavior of the protagonists and the outcome of military confrontations. But as we move to incorporate the ecological conditions and the behavioral events into an increasingly explanatory model, its representation will shift from the statistical mode to a more dynamic computerized simulation mode. Even with the advances of recent years in the statistical analysis field (Alt 1980), the problems of accurately capturing political processes as complex and interdependent as these remain nearly insurmountable. Thus, as the model becomes increasingly complete, we will rely less on statistical treatment and more on a computerized one.

\section{The decisional model}

While more detail is provided in the Methods and Procedures section, a few preliminary observations regarding the decision making simulation model are in order here. First, even though the research strategy to be used here seems the most appropriate and powerful at this stage in the development of the international politics discipline, its limitations should not be ignored. The critical limitation, of course, is that it rests on procedures that are quite indirect, requiring that we merely infer throughput on the basis of observed input and output. Therefore, as our findings increasingly suggest that certain sets of decision rules are not being used under certain ecological conditions and that certain other ones are being used, we would want to go the next step and begin to look inside the 'black box.' That operation, as we suggest above, would not make research sense now, but there is little question that we must eventually - if fuller explanation be the objective - get at the perceptions, preferences, and predictions of the decision makers as well as the interactions among them.

Let us shift now to the types of decision rules we might expect to find. There would seem to be three basic dimensions to the typology. First, and most generally, is the rationality dimension: to what extent do which types of national security elites, under which sets of conditions, follow which procedures of rational problem solving? Where, in other words, on the problem solving-to-random walk continuum do we find our decision processes? While this remains a constant preoccupation, this stage of our research can shed at best only indirect light on the question. Suffice to say here, the evidence to date is sufficiently mixed to suggest that the norm is not very close to either end of the continuum.

The second dimension, and the one that has captured much of the research attention in our field, is that of the 'driving force'. Do national governments, in their routine interactions with one another, respond primarily to domestic politics, internal and external economic incentives and constraints, military security considerations, ideological imperatives, geographical realities, or what? More particularly, when their interactions shift to crisis and confrontation, which of these factors are dominant? Once more, the body of speculative and systematic research is far from negligible, but the evidence remains inconclusive. Our reading of that evidence, however, is that all of these are at work in confrontational decision processes, but that the classical realpolitik factors typically become dominant, with a remarkable homogeneity across nations, cases, and time. To put it another 
way, we find fairly strong grounds for believing that considerations of domestic politics, economic goals, and ideological consistency do not disappear but become enmeshed with and interpreted in terms of the rather simple criteria of physical security. Hence, geographic, military, alliance, and diplomatic factors dominate in the model with which we work.

But even if it turns out that confrontational decisions are taken in a relatively rational manner and in response to traditional security considerations, a considerable latitude nevertheless remains. Thus, the third dimension in our decisional typology is that of hawk-todove, and it is the position that governments take on this dimension that will receive our research attention. There is no intention here of scaling state behavior on the rationality dimension or on the driving force dimension. We assume that confrontational behavior is purposive in orientation and relatively rational in its formulation. And we assume that the multiplicity of drives and interests will become more limited and focussed as a conflict escalates from the minor dispute to the military confrontation stage. There will be no empirical test of these assumptions here, whereas one of our major objectives is to ascertain the contextual and behavioral conditions that generate the range of hawkish and dovish moves that appear in these 900 or so confrontations.

\section{Methods and procedures}

Limitations of space as well as uncertainty as to specific methodological details always make this section of a proposal somewhat unsatisfactory. This is especially true, as is the case here, when a long-range investigation is in transition from one set of theoretical foci to another and thus from reliance on one set of methods to increasing reliance on other and less familiar methods. However, the summary that follows should offer a reasonably coherent description and rationale of the procedures that have been followed in recent stages and will be followed in the next several years.

\subsection{Preliminary statistical analyses}

As indicated earlier, the first of our proposed four phases is well underway, with the objective to better ascertain the contextual configurations under which the variables discussed previously tend to be associated with escalatory or de-escalatory behavior. Previous research has shown several of these associations to be inconsistent across time or across contexts defined by explicitly considered variables, and we need to better understand these configurations of variables before we can precisely specify the variables, parameters, and algorithms to be used in the computer simulation models.

Our analyses will proceed from those already reported (Stoll \& Champion 1980; Singer 1979); there, we employ multivariate contingency table analyses to help illuminate the varying associations between variables of interest and escalation, while controlling for third variables. Earlier analyses suggest that the associations that emerge rest on fairly complex, non-linear interactions of predictor variables, and our contingency table analysis strategy seems best suited for the somewhat exploratory analyses needed in this first stage of our next round of analyses (Fienberg 1977; Tukey 1977).

\subsection{The 'descriptive' computer simulation}

Once the results of the contingency analyses are in for the most important variables (late 1982), we shall begin intensive work on the second analysis stage, specifying and testing a computer simulation of the dynamic unfolding of a militarized dispute from the perspective of a given state's decision makers. We have already developed and tested several models that employ the general approach described previously. In the first (Stoll \& Champion 1980), we seek to account for the escalation of militarized disputes to a war/no war outcome on the basis of three unmeasured variables: the security-based stakes in the dispute, the likelihood of victory by one side should the dispute be 'resolved' by hostilities, and the degree of opportunity for the more 
powerful protagonist to retaliate against the 'provocations' of the much weaker state. The 'stakes' variable is indicated by a fairly simple function of the contiguity of a state to the site of the dispute, the extent to which its adversary is arming rapidly and/or allocating a high percentage of its resources to the military, and the prior conflict between the states; it is reduced by alliance and IGO (international inter-governmental organizations) bonds between the antagonists. The likelihood of military victory is indicated by differences in the military expenditures of the anatagonists, the availability of defense-pact allies to the target state, and the distance of the parties to the site of the dispute. 'Opportunity' is indicated by a vast disparity in military expenditures, the absence of major power allies on the weaker side, initiation of the military activity in the dispute by the weaker side, and the absence of bonds between the antagonists.

The model predicts escalation of the confrontation under either of two conditions: a) if both sides have high stakes in the dispute and both have a 'reasonable' chance of victory (i.e, there is essential military parity); or b) if there is a massive disparity in capability and the stronger side has ample 'opportunity' to use force against the weaker. Thus, the model can predict wars of aggrandizement by a strong state against a weak one and wars in which the sense of threat is more reciprocal (and when such considerations as the desirability of pre-emption or preventive war are relevant).

This simple model currently accounts for 25 of the 28 wars in a sample of 225 serious disputes involving at least one major power and occurring between 1816 and 1977 . Its success is marred, however, by a tendency to be 'alarmist' in its predictions; it falsely predicts that 37 additional disputes ended in war, when in fact they did not.

A later model developed by Stoll takes a more detailed look at both the escalation process and the decision making mechanisms of a 'typical' major power. It postulates that three separate 'organizations' - a military command, a diplomatic corps, and an intelligence service - separately monitor the course of an ongoing confrontation. The former two recommend (possibly different) responses (do nothing, threaten force, display force, use force, or go to war) whenever a military action is taken by its protagonist.

The military function considers several simple indices - relative military expenditures, distance to the site of the dispute, the recent won/lost records of the two sides, and the presence of major power allies - recommending escalation if the military situation is strongly in the choosing state's favor. The diplomatic function recommends escalation if the relations between the sides to the dispute have been unfriendly (many disputes or wars in recent years) and de-escalation if relations have been more positive (i.e, few disputes, no wars, and/or the presence of an alliance between the states). The intelligence function does not make a direct recommendation, but calculates the long term capabilities of the two sides, including other measures of national capability, as well as who has intervened in support of whom, and the non-disputant allies of each side. If the military and diplomatic functions make the same recommendation, that action is taken; if not, the overall capability balance returned by the intelligence function is considered. If that ratio is favorable to the deciding state, the more forceful action is taken; if unfavorable, the less forceful action is taken.

The next version of our computer model will build from and reflect the logic of both of these efforts, as we attempt to predict the behavior of State $\mathrm{X}$ as it responds to each new military action by its opponent (States $\mathrm{Y} 1 \ldots \mathrm{Yn}$ ) and its co-protagonists (States X1 . . .Xm). There will again be two fairly distinct sets of calculations: What are the stakes of the dispute, i.e., the potential gains and losses from a policy of escalation or war, and the probability that the use of military force would be successful. Again, the actual 'decision' to escalate would depend on both sets of considerations in a multiplicative fashion.

In the earlier models, the calculation of the 'stakes' was quite crude and undifferentiated; 
we will now use a larger number of variables in a more modular way. Here, the 'stakes' calculations would be modelled as a simple set of conditional and arithmetic decision rules yielding a positive value for 'hopes' and a negative value for 'fears'. For example, the degree of 'fear' associated with a state being militarily surpassed by an enemy might be specified:

IF (State Y has had many disputes with State $\mathrm{X})$

AND (State $Y$ is now weaker than State $X$ )

AND (State $Y$ is projected to be stronger than State $X$ in 5 years)

THEN Fear = Projected Relative Capability (C/Y) - Current Relative Capability

OTHERWISE Fear $=0$

Each such 'hope' and 'fear' calculation will yield a number that will be weighted by importance and summed to result in the total 'stakes' score. This can be seen as a 'recommendation' for or against escalation; a positive value will tend to produce escalatory behavior while a negative value recommends deescalation. But before a given action can be predicted, a recommendation to escalate must be weighted by the overall military/political balance of capability, i.e., the likelihood of successful military action. EFFECTIVE CAPABILITY is our label for the new abstract variable analogous to the "likelihood of success' calculation in the first model and the 'intelligence' function in our second computer model. It will consider the overall military situation, including the ability of all parties to reach each other and the site of the dispute, the likelihood and effectiveness of intervention by the allies of each side, and the longrun potential capability of both protagonists and their allies.

IF $(\mathrm{B} 1 * \mathrm{~S} 1+\mathrm{B} 2 * \mathrm{~S} 2+\ldots \mathrm{Bk} * \mathrm{Sk})$

*EFFECTIVE CAPABILITY $>\mathrm{Tl}$

THEN Escalate

OTHERWISE Do nothing

Where:

The Ss represent the values of each of the

k 'stakes' calculations,

Bs are the weights on each incentive

Ts are the threshold values sufficient to predict an escalation to conflict level 1

We shall use a number of variables in the stakes calculations which might be grouped by the specific 'hopes' and 'fears' to which they are relevant. Since we do not have data readily available on all the variables mentioned, nor the resources to collect them in the next two years, we will pursue them in somewhat separate but highly interdependent analyses. For those that appear promising but where data availability is problematic, the relevant 'stakes' calculations will be included only for a subset of historical cases (usually the years since 1945). Data for those variables that show particular promise, and discernibly add to the predictive power of the overall model, will be collected over the longer and wider empirical domain.

At present, the following considerations appear most important:

Pre-emption. Can state X prevail militarily in the current situation only if it strikes first? Here we will examine the extent to which the confrontations were characterized by the incentive to pre-empt, usually as a function of mobilization and transport logistics and weapons technology. Whether pre-emption actually occurred or not, the important question is whether cases that ended in war were indeed those in which the condition was present. In the nuclear-missile age, this would be a function of the survivability and lethality of the opposing weapon systems, but in 1914 for example, it was essentially a function of the mobilization plans and the transport systems upon which successful mobilization rested. Throughout the period under study, these conditions have appeared and disappeared in response to technological developments and changes in military strategy.

Preventive war. Are the long-term trends such that State $\mathrm{X}$ is about to be outclassed by State $\mathrm{Y}$ so that $\mathrm{X}$ considers it a choice between war now on its terms, or later, on Y's? This is quite similar to Organski's (1968) notion of the 'power transition,' a proposition that is associated with major power war, at least in 
the 19th century (Champion \& Stoll forthcoming). It addresses essentially the samequestion as the 'pre-emption' calculations above, but from a longer-term perspective. Here we would be looking at highly aggregated indices of military-industrial capability (see Bremer 1980) rather than at the details of the military situation in a particular dispute.

Economic Gain. Could State X obtain a valuable economic resource, market, or control of a trade route by force? While there has been little systematic research on 'the economic causes of war' in the past few decades, recent events have made these questions very salient. Here again, we will not be able to obtain data for the entire empirical domain, but we will obtain data on resource dependence/ trade, investment, etc. for the twentieth century major powers, and shall rely on coding of narrative sources concerning particular disputes, since adequate, reliable time-series data are very scarce on such variables before World War II and even into the present.

Territorial Gain. Could State X gain or regain by force control of a disputed or strategically important territory from State Y? We are well along in the collection of a data set on all territorial transfers by force or otherwise, and will also use the data and analyses generated by Weede (1973).

Inter-state Bonds. If State $\mathrm{X}$ is closely tied to State $Y$ in military alliances, diplomatic bonds, and similar IGO ties, military conflict would have disruptive effects far beyond the immediate issues at stake. Our data sets for these variables are complete.

Economic Ties. Close and well-managed economic bonds between states would impose high 'opportunity costs' on a policy of escalation. This data set is now being generated and should be ready by early 1982 .

After the initial specification and testing of this model has been completed, we will perform fairly extensive sensitivity tests on the variables and parameters. This should help us determine which considerations and variables do little to improve our ability to predict escalation, and hence can be dropped for reasons of parsimony, and should help us fine-tune the numerical parameters to maximize the model's goodness of fit. Also, we will expand the model to explicitly allow some parameters to vary across time and states. For example, a state with a history of unsuccessful war involvements seems likely to behave in a 'riskadverse' manner; that is, it would require higher incentives and/or a higher likelihood of success to take an escalatory act than might be expected from decision makers in a more typical state. Operationally, we will specify an additional set of routines that vary the ' $T$ ' (threshold) parameters as a function of the outcome of prior disputes and the gains/ losses from previous wars. Similarly, we will build from the work of Bueno de Mesquita (1978), who has used measures of the change in the polarity of inter-state alliance bonds to tap the orientation toward risk of national decision makers during confrontations. This fits with our hypotheses relating the 'structural clarity' of the international system to the likelihood of war (Singer \& Bouxsein 1975), and we now believe that the idea of escalation thresholds that vary as a function of such conditions can tap these concerns in the context of our emerging model.

\subsection{The 'explanatory' computer simulation}

In this last stage, we hope to devise and test a version of the model that incorporates a richer and more plausible conception of the psychological and organizational processes of decision making (Irwin 1971; Steinbrunner 1974). Unlike the model outlined so far, which is equivalent to a complex and nonlinear structural equation, this next model would be based on non-numerical, pattern matching procedures in the 'artificial intelligence' tradition (Simon 1969). For example, such a model might specify in some detail some stereotypical strategies to be pursued in international disputes, ranging from outright conquest to capitulation. The model would 
proceed in three basic steps: First, it would attempt to infer what the other side is 'up to'; that is, which strategy best accounts for its behavior. In doing so, the model would use the information it 'knows' about each strategy and the kinds of states that employ them. Next, its algorithms would choose an appropriate counter-strategy, using some sort of representation of the choosing state's goals and a 'counter-planning' procedure (Carbonell 1978). Third, the simulated government would apply the decision rules specified by the chosen strategy. This would involve monitoring the behavior of the target state to see if it corresponds to that 'desired' by the strategy, and taking the appropriate action. For example, a stragegy of coercion would specify that a threat be issued first (George 1971). If the specified behavior were not forthcoming (i.e., the response was defiance as in Leng 1980), the model would carry out the threat or, if conditions were not deemed appropriate by additional decision rules, it would allow its 'bluff' to be called. If the response of the other side were totally unaccountable, the whole process of inferring the strategy followed by the other side would enter another iteration (Ostrom 1977).

\section{Conclusion}

Since its inception a decade and a half ago, the Correlates of War project has focussed on one central problem: that of explaining the incidence of international war. It has been a slow and tedious process not only because of the absence of much prior work from which we might build, and the virtual absence of compelling models and relevant data sets. These problems have been compounded by the plethora of plausible hypotheses and frameworks, fluctuating priorities and shifting methodologies in political science, and erratic funding.

Yet our work has continued at a steady pace, producing a large number of high quality data sets (in wide use by researchers, teachers, and students here and abroad), a number of speculative, integrative, and conceptual articles, a long list of empirical studies, and a respectable flow of books. Equally important has been the training of nearly a score of doctoral and post-doctoral students, many of whom have since made important contributions to the disipline.

As the world moves once more back to the abyss of war, interest in our research has heightened considerably, making for (inter alia) a growing number of graduate students seeking to work in the international conflict field. The research that is proposed here represents a serious effort to build in a careful and creative way on the prior work that has been completed by our team and others, and to move as rapidly as possible toward a compelling explanatory theory of war. While it reflects our commitment to a careful, cumulative strategy, it is also responsive to theoretical and methodological developments in the field, as well as to the opportunities for that possible new insight that could suddenly illuminate the path and perhaps lead to a more direct and rapid advance in our knowledge.

\section{REFERENCES}

Alker, Hayward and Brunner, Ronald, 1969 'Simulating International Conflict'. International Studies Quarterly $13 / 7,70-110$.

Alt, James, 1980. Advances in Quantitative Analysis (special issue of Quality and Quantity 14/1.

Axelrod, Robert (ed.), 1976. Structure of Decision: The Cognitive Maps of Political Elites. Princeton, N.J.: Princeton University Press.

Barton, Richard, 1970. A Primer on Simulation and Gaming. Englewood Cliffs, N.J.: Prentice-Hall.

Bremer, Stuart, 1980. 'National Capabilities and War Proneness', in Singer (ed.) Correlates of War II. N.Y.: Free Press.

Bueno de Mesquita, Bruce, 1978. 'Systemic Polarization and the Occurrence and Duration of War'. Journal of Conflict Resolution 22/2, 241-67.

Carbonell, Jaime G., 1978. 'Politics: Automated Ideological Reasoning'. Cognitive Science, 2/1, 27-51.

Champion, Michael and Stoll, Richard. 'Capability Concentration, Alliance Bonds, and Conflict Among the Major Powers', in Alan Ned Sabrosky (ed.) Polarity and Warfare (forthcoming).

Choucri, Nazli and North, Robert, 1975. Nations in Conflict. San Francisco, Cal.: Freeman.

Dupuy, Trevor, 1979. Numbers, Predictions, and War. Indianapolis, Ind.: Bobbs-Merrill.

Fienberg, Stephen E., 1977. The Analysis of Cross-Classified Categorical Data. Cambridge, Mass.: MIT Press. Garnham, David, 1979. 'The Causes of War: Systematic Findings'. Milwaukee, Wisc.: Dept. of Pol. Sci. 
George, Alexander et al., 1971. The Limits of Coercive Diplomacy. Boston, Mass.: Little Brown.

Haas, Michael, 1965. 'Societal Approaches to the Study of War.' Journal of Peace Research II, 307-323.

Holsti, Ole, 1979. 'The 'Three-Headed Eagle: The US and System Change'. International Studies Quarterly, 23/3, 339-359.

Irwin, Francis, 1971. Intentional Behavior and Motivation. Philadelphia, Pa.: Lippincott.

Kegley, Charles, 1979. 'Measuring Transformations in the Global Legal System,' Onuf (ed.) Norm Making in the Global Community. Princeton, N.J.: Princeton Univ. Press.

Keohane, Robert and Nye, Joseph, 1977. Power \& Interdependence. Boston, Mass.: Littie Brown.

Leng, Russel, 1980. 'Influence Strategies and Interstate Conflict', in Singer (ed.) Correlates of War II. N.Y. Free Press.

Leng, Russell and Singer, J. David, 1977. 'Toward a Multi-Theoretical Typology of International Behavior', in Bunge et al (eds.) Mathematical Approaches to International Relations. Bucharest, Romania: Academy of Social and Political Science.

Organski, A.F.K., 1968. World Politics. N.Y.: Knopf.

Ostrom, Charles, 1977. 'Evaluating Alternative Foreign Policy Decision Making Models'. Journal of Conflict Resolution, 21/2, 235-265.

Richardson, Lewis, 1960: Statistics of Deadly Quarrels. Pittsburgh, Pa.: Boxwood Press.

Rummel, Rudolph, 1972. Dimensions of Nations. Beverly Hills, Calif.: Sage.

Simon, Herbert, 1969. The Sciences of the Artificial. Cambridge, Mass.: MIT Press.

Singer, J. David, 1968. 'Man and World Politics: The Psycho-Cultural Interface'. Journal of Social Issues, 24/3, 127-156.

Singer, J. David, 1979. 'The Management of Serious International Disputes'. Moscow: U.S.S.R. (IPSA Congress).

Singer, J. David et al. 1972. Capability Distribution. Uncertainty, and Major Power war, 1820-1965. In B.
Russett (ed.) Peace, War, and Numbers, Beverly Hills, Calif.: Sage.

Singer, J. David, 1981. Accounting for International War: The State of the Discipline. Journal of Peace Research 18/1, 1-18.

Singer, J. David and Bouxsein, Sandra 1975, 'Structural Clarity and International War: Some Tentative Findings', in Murray (ed.) Inter-disciplinary Aspects of General Systems Theory 126-135.

Steinbrunner, John, 1974. The Cybernetic Theory of Decision. Princeton, N.J.: Princeton Univ. Press.

Stewart, Philip D., 1976. 'Diversity and Adaptation in Soviet Political Culture: The Attitudes of the Soviet Political Elite.' In J. P. Shapiro and P. J. Pstichnyj (eds.) Change and Adaptation in Soviet and East European Politics. N. Y.: Praeger, 18-39.

Stoll, Richard, 1979. To the Brink of War: Major Power Disputes, 1816-1975. Ann Arbor, Mich.: Ph. D. Thesis.

Stoll, Richard and Champion, Michael, 1980. 'Predicting the Escalation of Serious Disputes to International War: Some Preliminary Findings', Ann Arbor, Mich.: Correlates of War Project.

Sullivan, Michael, 1978. 'The Causes of War: An Evaluation of the State of Theory'. Tucson, AZ.: Dept. of Polit. Sci.

Tukey, John, 1977. Exploratory Data Analysis. Reading, Mass.: Addison-Wesley.

Weede, Erich, 1973. 'Nation-Environment Relations as Determinants of Hostilities among Nations'. Peace Science Society Papers 20, 67-90.

Whiting, Allen, 1975. The Chinese Calculus of Deterrence. Ann Arbor, Mich.: Univ. of Michigan Press.

Wright, Quincy, 1942 \& 1965. A Study of War. Chicago, Ill.: Univ. of Chicago Press.

Wright, Quincy, 1965. 'The Escalation of International Conflict'. Journal of Conflict Resolution 9/4, 434-449.

Zinnes, Dina, 1980. 'Empirical Evidence on the Outbreak of International Violence'. In Gurr (ed.) Handbook of Political Conflict. N.Y.: Free Press. 